\title{
Poesía religiosa de Manuel Botelho de Oliveira
}

Ignorados de bibliógrafos e historiadores de la literatura brasileña, aunque ya habían sido registrados hace casi un siglo por Rivara, ${ }^{1}$ existen en la Biblioteca Pública de Évora dos libros manuscritos titulados respectivamente Lira sacra, en verso, y Conceitos espirituais, en prosa, ambos religiosos y debidos a la pluma de Manuel Botelho de Oliveira, conocido hasta ahora sólo por su Música de Parnaso (1705), la primera obra poética publicada por un hijo del Brasil, según ufanamente declaraba su autor: ${ }^{2}$

1 Joaquim H. da Cunha Rivara, Catalogo dos manuscriptos da Bibliotheca Publica Eborense (Lisboa, 1850-1871), II (1869), 93; IV (1871), 62.

2 Musica do Parnasso dividida em quatro coros de rimas portuguesas, castelbanas italianas \& latinas Com seu descante comico redusido em duas comedias. Lisbca: Miguel Manescal, 1705. Aquí citamos por la ed. A. Nascentes, 2 vols. (Río de Janeiro, 1953), 1, 3.

El primero de los códices citados (signatura CXIV / 1-4), es un vol. en $4^{\circ}$, de $127 \mathrm{ff}$. ns., precedidos de portada que reza: Lyra Sacra / Em uarios assumptos / Dedicada / Ao Illusariss[im]o Senbor Marques / de Alegrete, do Conselbo de / Estado de suca Mag[esta]de / e seu Veador da faz[en]da / Escrit[a] / Por Manoel Botelbo de Oliu[ei]ra / Babia 12 de Setembro de 1703. Parece -si no es autógxafo- manuscrito original, y ya preparado, con dedicatoria y prólogo al lector, para la impresión, salvo las licencias. En la dedicatoria al marqués de Alegrete, firmada en la fecha mencionada, declara el autor haber escrito esta obra mientras aguardaba la publicación de Música do Parnaso. De ser cierto esto, Lira sacra se compuso en un año o poco más, pues en Música hay versos (I, 229-232) fechables alrededor de 3 de julio de 1702. Botelho debió enviar su Lira a Portugal tal vez en $1703 \mathrm{y}$, desde luego, antes de 1705 , pues que da como inédita Música. El marqués de Alegrete, D. Manuel Telles da Silva, murió el 12 de septiembre de 1709, exactamente seis años después de que el poeta le dedicase Lira. Botelho ie siguió en 1711. Ignoro qué razones impidiesen la publicación de Lira. No seríar. económicas, porque el autor era tan rico que prestaba dinero al Estado; y la religiosidad de la obra es la común en la época, aunque sin duda el Santo Oficio hubiese preferido suprimir o modificar alguna composicion, como luego se verá.

En el códice CXXIII / 1-24, en 40, de 116 ff. s. n., vienen los Conçeitos spirituais./ Aubborizados com os lugares da Escritura / Sagrada, sobre os dez mandamentos / da Ley de Deus, sobre os sete pec-/ cados mortais, sobre os / quatro Nouissimos do Homem./ Escrittos / Por Manoel Botelbo de Oliueyra,/ fidalgo da Caza de S. Mag[esta]de / Anno de 1706. Según Rivara es MS autógrafo, cosa que no puedo comprobar. Si éste lo es, el de Lira, rubricado de modo diferente, 
Creo innecesario encarecer la importancia de estos escritos para los estudiosos de las letras brasileñas. Los dos, por su tema y estilo, muestran una dimensión tan en cierto modo insospechada en el autor de Música do Parnaso, que sin tenerlos en cuenta no se podría hacer una apropiada estimación del perfil literario de Manuel Botelho de Oliveira.

Aunque en ocasiones nos referiremos a Conceitos espirituais, el objeto de nuestro estudio será Lira sacra, que es la obra más ambiciosa y de mayor interés. ${ }^{3}$

La primera sorpresa que nos of rece este nuevo escrito es que, contra lo esperable del mundano autor de Música do Parnaso, un libro esencialmente laico, en Lira sacra todo es religioso. María, Jesucristo, una selección representativa de los santos (apóstoles, mártires, padres de la Iglesia, fundadores, filósofos, etc.), amén de consideraciones morales y jaculatorias devotas, son los asuntos de la obra. $\mathrm{Y}$ en ella sobresalen tanto la aspiración exhaustiva de tratar todos los posibles aspectos del mundo católico, ${ }^{4}$ como un definitivo gusto por la organización: el libro se divide en dos partes aproximadamente iguales, en las que se repiten los temas, presentados por orden histórico y en proporción acordada a su importancia. Botelho regula su musa de tal modo que los 126 sonetos de la primera parte

es de otra mano. Lo más probable, considerando la buena letra y las costumbres de la época, es que ambos sean hechura de pendolistas profesionales que trabajaron sobre borradores de Botelho.

3 Cumpliendo lo prometido en el título, el texto de Conceitos espirituais aparece repartido en dos columnas: en la primera vienen los conceitos y en la otra los lugares de la $V$ ulgata con que se autorizan aquellos. Como lo que hace Botelho es casi una traducción de los textos bíblicos, el mérito de la obra está en la selección de los pasajes de la Escritura y su combinación de manera que formen una agudeza las más de las veces inexistente en la fuente. Sirvan de ejemplo estos párrafos sacados de la parte sobre la muerte, de las mejores del libro, y en la que con desengañado $\mathrm{y}$ repetido ubi sunt príncipes, hermosas, ricos y sabios, parece Botelho recrear famosa escena de El gran teatro del mundo calderoniano ("A gloria deste mundo he hûa figura de comedia que brevemente passa", "Morte", $\S$ ii): "...Que aproveita à molher mais fermoza o lindo gesto, que não he mais que huma sombra de pintura, que passa como sombra? E quando cuida essa belleza que he flor da vida, tem a vida da flor. Dizeme pois, onde estäo aquelles bellissimos objectos? He certo que ja cessou a memoria delles. Onde estão aquelles olhos e aquelles cabellos que te ferião o coração? E se antes exâo seus cabellos fios de ouro, te fazem agora derramar as lagrimas em fio. E se erão seus olhos como estrellas no ceo de seu rosto, podemos dizer que cahiram do Ceo estas estrellas..." Las fuentes de este pasaje ("Morte da fermoza", $\$$ viii-ix) figuran en la segunda columna: "Umbra picturae (Sap xv. 40); Et fugit velut umbra (Job xiv 2); Tamquam flos agri, sic efflorevit (Psalm. cii.15); Dixi: ubinam sunt? Cessare faciam ex hominibus memoriam eorum (Deut. xxxii.26); Vulnerasti cor meum in uno oculorum tuorum et in uno crine tuo (Cant. iv. 9); Caput ejus aurum optimum (Cant. v.11); Mortua est ...ut plangeret, et fletet eam (Genes. xxiii. 2); Nitentibus oculis (Esther xv.8); Et stellae cadent de caelo (Math. xxiv.29).'

4 Incluidas las fobias del tiempo (sonetos 122 y 123 , contra hebreos y herejes) y algún remedo misticoide (ff. 96v-97v). 
(ff. 4-67) se distribuyen simétricamente: 20 a María, 43 a Cristo, 43 a varios santos, 20 a festividades $y$ asuntos morales. ${ }^{5}$ En la segunda parte (ff. 68-127) se dedican 3 composiciones a María, 9 (una de ellas mayor) a Cristo, 9 (una también mayor) a los santos, 5 a festividades y temas morales. ${ }^{6}$ Para amenizar tanto cálculo Botelho alega en el prólogo la variedad de metros ("para que fosse menos fastidiosa a leitura e mais suave o entretenimento") y de estilos: "misturei entre os versos sérios alguns jocosos, porque... a diversidade do estilo provocasse melhor o gôsto".?

Vista la ausencia de la religión en Música do Parnaso, obra donde Eotelho reúne versos en su mayor parte escritos en años mozos, cabria preguntarse si Lira sacra no representa la vuelta a lo religioso de un hombre antes más sensible a intereses mundanos, y que al llegar a casi sus setenta, desengañado de vanidades, experimenta, entre 1702 y 1703, una conversión moral y artística al modo de la del santo juglar de Asís, que el bahiano nos recuerda: "Deixa o poeta a musa celebrada/ e busca o canto do celeste templo" (f. 73). Contra esta suposición hay en el libro dos romances castellanos que, según especifica el autor (ff. 124v-127), se cantaron en la fiesta de la beatificación de San Juan de la Cruz, suceso de 1675. Es decir, Botelho tenía escritos versos religiosos en fecha muy anterior a 1702-1703, y si no los incluyó en Música do Parnaso, es porque tal vez pensaba ya tempranamente en hacer libro aparte con ellos. De cualquier modo, lo más posible es que, en efecto, Botelho hubiese abultado considerable y apresuradamente Lira sacra en el corto período 17021703 , si atendemos a la poca lima de no escasas composiciones de este libro, faltas de aquel elaborado acabamiento que, aún en las menos inspiradas, mostrara el poeta en Música do Parnaso. Quizás consciente de esto, Botelho quiso ampararlo bajo la excusa de que su intención religiosa exigía una "veia pobre" (f. 70); sin embargo, como luego se verá, ésta sólo puede justificar su gusto conceptista, no el frecuente desmayo de una pluma con prisas.

\section{Primacía de lo portugués Sobre lo Castellano}

Otra inovación de Lira sacra respecto a Música do Parnaso se refiere a la lengua en que se escribió. A la preferencia por lo castellano en Música

5 Estos últimos en realidad son 17, pero Botelho cometió error en la numeración y pensó haber escrito 20.

6 Romances, redondillas, décimas, octavas, canciones y silva son los tipos de composición y estrofa de esta parte.

7 En las citas de Lira sacra resuelvo abreviaturas y modernizo la ortografía, salvo en algún caso de importancia lingüística. 
do Parnaso, manifiesta en los hechos (los versos españoles, incluidas las comedias, son mayoría) y en las palabras de la dedicatoria ("...entre as demais nações do mundo parece que aos espanhóis adotaram as Musas por seus filhos, entre os quais mereceu o culto Gôngora extravagante estimação, e o vastíssimo Lope aplauso universal..."), se opone la primacía indisputable de lo portugués en Lira sacra, donde los versos castellanos son minoría ${ }^{8}$ y donde hay un elogio de la poesía lusitana que, expresado casi con los mismos términos con que se laudó la española, parcce intencionada palinodia de aquel homenaje. Dice así Botelho en la dedicatoria de Lira sacra al marqués de Alegrete:

Bem quisera eu dedicar a V. Excelência em idioma latino estas rimas sacras, porém como a língua portuguêsa se tem levantado com a poesia, podemos dizer que as Musas são da nação portuguêsa; e ainda em tempo de menos elegância poética, chegou o nosso Camões a tanto aplauso com suas Lusiadas, que se traduziu em várias línguas o seu poema, quetendo todas as nações criar aquêle parto português, quiçá como enjeitado de sua fortuna. Despois foram crecendo em nosso Portugal poetas insignes, assim no estilo heróico como no lírico, que deram nôvo crédito à nossa língua, que se acomoda muito às frases mais elegantes e os conceitos mais profundos. Pelo que, imitando a tão grandes engenhos, escrevi estas rimas em lingưa portuguêsa...

Giro tan radical acaso se deba, más que a tazones políticas, ${ }^{9}$ al alejamiento, con la edad, del entusiasmo por la poesía española, seguramente nacido en sus años de estudiante en la Península. También la índole religiosa del libro debió inclinarle hacia la lengua materna. Los Conceitos espirituais, su última obra y de religiosidad más estricta, están escritos exclusivamente en portugués.

Observemos, en fin, que, lo mismo aquí que en Mísica do Parnaso, Botelho de Oliveira se siente muy portugués, pero del Brasil: "Este parto poético que nas horas de minha ociosidade, ou para melhor dizer, da mais

8 En castellano vienen dos glosas en décimas (ff. 96v-99) y seis romances (ff. $118 \mathrm{v}-127)$.

9 En 1703 portugueses y españoles luchaban en el Brasil por la Nova Colonia do Sacramento y en la Península se enfrentaban en la Guerra de Sucesión. Pero en Música el que Botelho glorificase a héroes portugueses de guerras contra España, no interfirió con su gusto por lo español. Pot otro lado, ya venemos que, a pesar del homenaje a Camões (un tanto enfriado for ese "tempos de menos elegância poética"), en Lira cuentan mucho los aquí silenciados modelos castellanos. 
útil ocupação, produziu meu discurso, sai à luz do berço do Brasil pará os olhos de Europa."10

CONCEPTISMO: LA "VEIA POBRE" COMO NORMA POÉTICA

La tercera novedad de Lira sacra tiene que ver con el estilo. Botelho abre su libro (soneto 1) invocando la inspiración de la "Celeste Musa", la Virgen María, para que, enseñándole "melhor metro", le ayude a volver su canto a lo divino: "Inspirai que ao divino entoe o canto." Esta. conversión se hace empobreciendo el viejo canto, el humano. El mejor metro para Dios es el humilde, piensa Botelho, como si esto fuera exigencia del género y una prueba de auténtico sentimiento religioso. Así, dice a la Virgen María: "e se humilde louvais de graça cheia,/ meu verso por humilde vos agrada" (son. 1), y a San Francisco de Asís: "mas se ser pobre e humilde vos agrada,/ terá meu verso de aplaudido os fôros,/ porque haveis de estimar, Francisco santo,/ se a veia pobre fôr se humilde, o canto". 11

Pero conviene aclarar que tal pobreza de estilo significa principalmente un alejamiento de la pomposa "Musa sublimada", altiva productora de "os verso mais sonoros" (ibid.), pero no de un "plectro doce e fino" (son. 1), pulsado por un ingenio que se aprecia de agudo discurrir ("em rimas sacras meu discurso afino") al servicio de alambicado fruto: "os conceitos mais profundos" (f. 1).

Es decir: esta proclamada "veia pobre" consiste en pobreza de sonoridades y brillos culteranos, a favor de conceptismo. La orientación estilística de Lira sacra, pues, es radicalmente opuesta a la de Música do Parnaso, donde aunque las agudezas son abundantes, lo sobresaliente es la factura culterana. Y si ya en esta obra el culteranismo se manifestaba en un tono menor por la simplicidad sintáctica y alusiva, así como por el predominio de las composiciones reducidas y versos de arte menor, en Lira sacra, a esto se añade una desatención casi absoluta a las dimensiones sensoriales del verso. Son raras aquí las enriquecedoras alusiones, las imágenes y léxico suntuatio, la nota de color o de sonido. Hasta el empleo de las fórmulas de simetría, tan conspicuo ahora como en el libro anterior, sufre una purga de posibilidades sensoriales, quedando aquéllas re-

10 Lira, f. 2, "Ao leitor". La alusión a, lo brasileño no vuelve a surgir sino en los sonetos $107 \mathrm{y} 108$, por los cuales sabemos que el autor poseía dos ingenios de azúcar, uno en Tararipe y otro en Jacomitím.

I1 Lira, f. 70. Cervantes, en su canción, llena de ecos garcilasianos, "A los éxtasis de Nuestra Beata Madre, Teresa de Jesús" (BAE, I, 710), declara semejante estética. 
ducidas a incoloro vehículo normativo de conceptos antitéticos..$^{12}$ Basta comparar composiciones de Muisica do Parnaso como, por ejemplo, las tituladas "Anarda sangrada" (I, 54-56), o "Anarda colhendo neve" (I, 57-59), con los versos de Lira sacra a Cristo - sangrando apenas "divino orvalho"- en "As agonias do Horto" (son. 33), a Cristo desnudo (son. 44), al martirio de San Sebastián (son. 82) o a las llagas de San Francisco (ff. $75 \mathrm{v}-76 \mathrm{v}$ ), para ver cómo, ante el tentador blanco y carmín de análogos modelos, en el libro religioso se desaprovecha voluntariamente la oportunidad de aquel coruscante derrochar marfiles, llamas, nieves, rosas, platas, corales y nácares que tan elegantemente ornó Música do Parnaso.

Pero si el cuerpo desnudo de San Sebastián no convoca nieves en los versos de Lira sacra, las flechas que atraviesan las carnes del santo sí hacen más aguda la pluma del poeta:

\author{
Valeroso ao martírio se mostrava \\ vosso peito que as setas não temia; \\ se vosso peito cândido vencia, \\ alvo das setas vosso peito estava..$^{13}$
}

\footnotetext{
12 La gongorina bimembración del verso (ver Dámaso Alonso, Estudios y ensayos gongorinos, Madrid, 1955, p. $117 \mathrm{ss.)}$ se manifiesta en Música copiosamente $\mathrm{y}$ en todas sus varias modalidades, incluidas con destaque las expresivas de un puro halago de los sentidos, como son las bimembraciones fonética, colorista y rítmica, realzando el final (f) de estrofa: "as bandeiras tremer, tremer a terta" (f) I, 93; "com raios de rubi, raios de prata" I, 97; "la flor de rosicler, el fruto de oro (f) I, 208. En Lira la frecuencia del procedimiento no disminuye, pero son raros dos casos de bimembración del tipo mencionado, y aun éstos suelen aparecer subordinados a agudeza conceptual. Así, en f. 92 ("A Cristo crucificado"): "E nesse Ocidente estais / qual sol posto entre fulgores:/ êle de purpúreas côres,/ vós de purpúreos sinais" (f); y en f. 119v ("Ao nascimiento de Cristo"): "Perlas desperdicia el Niño, / y si nuestra sedención / agora perlas le cuesta, después rubíes le costón". (f). Igual resultado of rece una comparación entre versos correlativos (otro homenaje de Botelho a Góngora) de Música (cfr. I, 12, 66, 172) y de Lira (sonetos 3, 26, 71, 97, 118; ff. 68v, 69v): aquí se edifican sobre secas pluralidades de conceptos (gula, ambição, vanglória, esperança, fé); allí, sobre resplandeciente vibración de los sentidos: estrêla, jasmim, sol, mariposa, nieve.

13 Soneto 82. Autorizada por Gracián (Arte y agudeza de ingenio xxxii), la agudeza hecha sobre la bisemia de alvo 'branco' y 'ponto a que se dirige o tiro', la había empleado ya Lope de Vega, Rimas sacras (1614), en versos a la Eucaristía (son. Ixxxvi, f. 176); cf. también su son. lxii, "A San Sebastián" ("Tiravan Dios y el hombre al blanco un día"), que inspira el final del de Botelho. Otro autor imitado por el poeta brasileño, y cuya obra debió conocer en copias manuscritas, fray Jerónimo Bahía (ca, 1620-1688), repite el mismo juego en versos eucarísticos: "Por alvo vos tem o mundo,/ Pão que o mundo fazeis alvo." (Fênix Renascida [Lisboa, 1716-1728], II, 305) y en otros "Ao Menino Deos nascido" (ibid., p. 311).
} 
Y si las llagas de San Francisco ahora no destilan rubíes, son conceptuosa copia del amanuense divino:

Fêz o divino Pai uma escritura

na cruz de Cristo com picdoso intento, sendo do sangue seu a tinta pura, escrito o amor com pena do tormento; mas, como para a patria mais segura

o Verbo se partiu sanguinolento, quis deixar em Francisco autenticado, em falta de escritura, seu traslado. ${ }^{14}$

Vemos, en definitiva, que por este deseo de humildar su musa, Botelho se aparta del culteranismo, pero no de Góngora, pues bajo la aparente modestia de esa falta de brillos culteranos y esa facilidad estilística, en las mejores composiciones de Lira sacra Botelho aspira a la misma complejidad semántica y altivez de mira poética del Góngora admirado por Gracián. El poeta bahiano, en el prólogo de este segundo libro y después de recordar que "tem a poesia muita conexão com as influências do Céu", no puede esconder la satisfacción (análoga a la de Góngora respondiendo a Pedro de Valencia) de advertir al lector que, sin un previo conocimiento de las Sagradas Escrituras y hagiografía, no podrá "entender o conceito" de sus versos..$^{15} \mathrm{Y}$, en suma, traiciona su impuesta humildad al declararnos con un aristocratismo muy a lo Gracián que el alambicamiento de sus agudezas se procesa a partir de algún lugar de la Escritura, de "donde - dice- levanto o pensamento para cair o conceito".

\section{MODALIDADES DEL CONCEPTO: AFÁN DE SIMETRÍA}

De acuerdo con la definición gracianesca del concepto ("acto del entendimiento que exprime la correspondencia que se halla entre los obje-

14 F. 26v, octava 26. En el romance de Lope de Vega "Al Seráfico Padre San Francisco" (Rimas sacras, ff. 185v-186), cuéntanse las bodas del santo con Humildad y Pobreza; Cristo es el padrino y ofrece como dote sus cinco llagas: "Hácense las escrituras, / y escribe Dios de su letra/ en sus pies, costados y manos / lo que ha de haber de su hacienda." En "Otro [romance] a las llagas" (f. 187) un "serafín crucifijo" se aparece a San Francisco y, "haciéndose todo un sello, con ser su ser infinito,/ imprimióle como estampa,/ viéndole papel tan limpio,/ en el cuerpo a Cristo muerto,/ y en el alma a Cristo vivo."

15 También se enorgullece de la dificultad de sus Conceitos espirituais cuando notifica al lector: "este liuro pello trabalho comque está composto, tem sua singularidade, e porque authorisar os conçeitos com os lugares da Escritura Sagrada he empenho tão difficil, que pella difficuldadee delle, fas admirau la traça" (p. [3]). 
tos"), las aventuras estilísticas de Lira sacra se pueden resumir esencialmente en el propósito de establecer - como decía el escritor aragonésel careo o confrontación entre dos términos, buscándoles "alguna correlación o consonancia entre las circunstancias adyacentes" (Arte lix) para extremar la paridad; o bien, tomar esa inicial conformidad en algo "como fundamento para ponderar después la discordancia en los demás efectos" (ibid.). Y así en el soneto 34 de Botelho, José y Jesú se acomodan tanto por paridad fonética como conceptual, pues que ambos fueron vendidos. Y en el f. 104 la agudeza por disparidad entre la Torre de Babel y Pentecostés se establece sobre una circunstancia común, el lenguaje: allí, confusión de lenguas; aquí, don de lenguas. $Y$, como la paronomasia en el ejemplo anterior, en éste la bimembración antitética del verso refleja el careo conceptual. Dice el poeta al Espíritu Santo:

Hoje trocais docemente de Babel as arrogâncias, que se êste fêz várias linguas, boje fazeis linguas várias. (f)

Com grande diferença:

que naquelas por jactância

ficou a fala confusa,

nestas, entendida a fala. (F) ${ }^{16}$

De manera análoga, en el soneto 40 se contrapone la columna ígnea o de nubes que guió al pueblo de Israel en el desierto (Éxodo xiii, 21-22), a la columna a que fue atado Cristo en su Pasión:
Destes, Senhor, a vosso povo caro
a coluna por pio ministério
da noite tenebrosa e dia claro;
mas, trocado em afronta vosso império,
se a coluna lhe destes para amparo,
a coluna vos dão por vitupério. (F)

No faltan ejemplos de rebuscada extravagancia, como el del soneto 79 , al martirio de San Pablo, cuya cabeza cortada dio saltos comparables a los de Juan el Bautista en el vientre de su madre durante la visitación de María (Lucas i, 41):

16 Uso las abreviaturas de Dámaso Alonso (ver nota 12) para indicar la posición de la simetría bilateral en el poema: al principio $(P)$, al final de estrofa $(f)$ $y$ al final de composición $(F)$. 
Cortam-vos a cabeça esclarecida

e saltais de prazer ao golpe forte, como João na graça conseguida.

Mas nesta ação mostrais mais alta sorte, que êle de prazer salta tendo a vida, vós saltais de prazer logrando a morte. (F ${ }^{17}$

Los ejemplos podrían multiplicarse. Todo el libro está lleno de careos de personas (Eva-María, Adán-Cristo), montes (Tabor-Calvario, Calvario-Sión), huertos (el de los Olivos-el de José de Arimatea), escaleras (del templo de Jerusalén-escala de Jacob), números (cinco sicloscinco llagas, en seis días hizo Dios el mundo-en seis deshizo el mundo a su Dios), fuegos, crepúsculos, árboles, etc. $\mathrm{Y}$ al servicio de tales confrontaciones conceptuales pone Botelho los procedimientos corrientes de agudeza verbal, desde el poco glorioso jugar del vocablo, ${ }^{18}$ las fáciles paronomasias, ${ }^{19}$ y la ambigüedad de la puntuación, ${ }^{20}$ a los equívocos, en particular los jocoserios, construidos sobre frases hechas al estilo de estar nos seus treze (f. 95), ser mäo perdida, ${ }^{21}$ o bien ser arrebatado, fazer as coisas no ar, estar fora de si, apanbar descalço ('apanhar não pronto'), aplicadas a San Juan de la Cruz (ff. 95v-96), y en las cuales se alude a sus éxtasis místicos y orden religiosa. Del mismo santo escribe:

Não sei que briga ou desvêlo

com vós teve o mundo errado,

17 Botelho no evita estas ridiculeces devotas, abundantes en algunos de sus modelos. Para probar la pureza de la Virgen María dice, aludiendo con dudoso gusto a su preñez: "Se outra cousa não pode ter entrada / no lugar que por cheio de graça se contenta,/ sendo cheia de graça em vosso estado,/ não cabia lugar para o pecado" (f. 68). Y sobre el martirio de San Pablo se le ocurre (son. 79): "e quando tendes o martírio aceito,/ derramastes o leite que no peito / tinha vossa pureza congelado."

18 En f. $100 \mathrm{v}$ Botelho dice que la Hostia es "quintaessência" medicinal, preparada por un Dios de "essência trina". Por lo visto el poeta necesitaba darle un repaso a su catecismo, pues vuelve a resbalar en f. 117: "essência divina", "una e trina."

19 En el f. 80 se lee: "mais que maná do Céu, mana a doçura"; otros ejemplos: "se sois de hereges martelo,/ sois de amor amattelado" (f. 95); "Que aproveita à fermosura /. tanto asseio, tanto alinho,/ se é seu castigo uma campa / quando campa em seus delírios?" (f. 109). Esta última agudeza hace recordar la de Ledesma, "En una cama de campo/ estaba Cristo a la muerte,/ que en cama de campo nace / y en cama de campo muere...", citada por Gracián en su Arte xxxiii. Otros casos de paronomasia hay en los sonetos 18, 93, 96.

20 ". . estoy tan tierno por vos,/ que si pudiera ser Dios,/ os diera todo mi ser. . " (f. 95).

21 En el son. 36: la bofetada recibida por Cristo "bem se pode dizer, foi mão perdida", jugando con expresión del lenguaje de los jugadores. 
pois creio que de enfadado

vos deu o mundo um capelo. ${ }^{22}$

Otra agudeza a costa de frase proverbial hay en estos versos sobre los milagros de San Antonio de Lisboa:

Todos veneram absortos
vossos milagres, porém
sem dizer mal de ninguém,
desenterráveis os mortos. ${ }^{23}$

Por otra parte, y como ya es manifiesto en los ejemplos citados, todo cotejo conceptual presentado por Botelho suele subrayarse estilísticamente por la simetría bilateral del verso. Bimembración de un solo verso al final de estrofa: "no ventre luz, no nacimento clara" (f. 73); las más veces antitética: "contra os tiros de ardor, balas de neve" (f. 72). También, y con mucha más frecuencia, bimembración repartida en los dos versos $^{24}$ que inician una composición (P), o que rematan estrofa (f) o composición (F):

Eva, primeira mãe da gente humana, Adão, primeiro pai da humana gente. (P)

Por outra Eva, outro Adão, da mesma sorte, entrou a Redenção contra o pecado, entrou a vida contra a morte. (F)

(son. 5).

de sorte que êste Sol esclarecido

no Ocidente da Cruz foi sepultado,

no Oriente da Mãe foi renascido. (F)

(son. 57)

Botelho a veces intensifica la simetría de la bimembración, ya variándola

22 F. 96. Capelo 'capuz de frades' y 'repreensão'. Igual chiste, aplicado a fraile maltratado por su arzobispo, hay en Gregorio de Matos: "Que ha de levar um capelo,/ se não leva um capelão?" (Obras, ed. Academia Brasileira, V, 146).

${ }_{23}$ F. 94v. Desenterrar os mortos significa también, como en español, 'murmurar, hablar mal de alguien'. Y hasta parece que Botelho se hubiese inspirado en Quevedo, Vida del buscón vii, donde se dice que la madre de Pablos, una bruja, "está presa en la Inquisición de Toledo porque desenterraba los muertos sin ser murmuradora".

${ }_{24}$ Otros ejemplos de bimembración en un solo verso, en sonetos $11,54,61$, $90,114, y$ f. 87 . Simetría repartida en dos versos hay en sonetos $7,27,34,38$, $43,49,58,62,66,68-70,76-78,80,88,90,103,112,114$. 
con ordenaciones quiasmáticas, como en el ejemplo anterior y en este del f. 109:

$$
\begin{aligned}
& E \text { todo o garbo fermoso, } \\
& \text { é todo o belo capricbo, } \\
& \text { cristal aos longes da morte, } \\
& \text { aos pertos da morte, vidro. }
\end{aligned}
$$

ya siguiendo análogos procedimientos de repetición, como el - tan grato a Góngora - formulado $A_{1}(x, y)-A_{2}(y, x)$ por Dámaso Alonso, ${ }^{25}$ y manifiesto en los siguientes remates de los sonetos 50,60 y 63 :

Se ao sexto dia a Criação consuma, consuma a Redenção ao sexto dia. (F)

Elias sobe arrebatado em fogo,

Cristo em fogo de amor arrebatado. (F)

naquela, um Deus em homem se transforma,

e neste, em Deus um homem se converte. (F)

La pasión de Botelho por las ordenaciones simétricas del verso, ya bien notable en Música de Pamaso, se torna en verdadera manía en Lira sacra, donde no se contenta con el empleo abusivo de las mencionadas fórmulas, amén de versos correlativos (cfr. nota 12), sino que cae en otras prácticas de gusto muy inferior. ${ }^{26}$

\section{Fuentes de "LiRA SACrA": poesía a lo divino}

La fuente principal de Botelho es, como él mismo declara, la Biblia. Pero hay que notar que, aunque en alguna ocasión sigue de cerca los textos religiosos, ${ }^{27}$ lo más frecuente en este libro, y también en los Con-

25 Estudios y ensayos gongorinos, p. 172. Otros ejemplos hay on los sonetos $8,45,53,87,91,104$, así como en la glosa (ff. 98-99) a versos de Lope de Vega que ya traen el artificio. La fórmula $A_{1}(x, y)-A_{2}(z, y)$ se muestra en Ios sonetos 39 y 44; y de $A_{1}(x, y)-A_{2}(x, z)$ hay casos en los sonetos $55,56,61,79$.

26 Cfr. son. 113, con anáfora en nueve versos; son. 115, con cada uno de sus versos afectados de anadiplosis; son. 23, "Ao nome de Jesús, repetido em todos os versos", y son. 109, donde repite la palabra passos en cada verso. Los sonetos 120 y 121, por otros conceptos, también anuncian la perversión del gusto que aquejará las academias poéticas del Brasil del siglo xvmr.

27 Así en la "Silva à Assunção da Senhora", los versos "Quem é esta que sobe como Aurora,/ fermosa como alva,/ eleita como Sol, que a luz é sua,/ te. rrivel ao demônio sempre armado,/ como esquadrão nas praças ordenado?" (f. 83v), remedan los del Cantar de los Cantares vi.9: "Quae est ista, quae progreditur quasi aurora consurgenș, pulchra ut luna, electa ut sol, terribilis ut castrorum acies ordinata?"; y el soneto 13, "Ao pé da cruz estava doloroșa / a Mãe...", parafrasea el himno "Stabat Mater dolorosa". 
ceitos espiritudis, no es que el poeta tome la Escritura como modelo 1iterario, sino que utilice, con caprichosa y hasta extravagante libertad, la erudición sacra para construir agudezas. Asi, el versículo "Ecce tu pulchra es, amica mea ...oculi tui columbarum" (Cant. i.14) y la alusión a la oferta de dos palomas en el templo, necesarias para la purificación de la mujer (Lev. xii.8; Lucas ii.24), fundamentan el concepto final del soneto 99, al martirio de Santa Lucía:

Se o amor divino nas esposas suas

olhos de pomba tem, a Deus mostrastes

melhor oferta com verdades nuas;

porque na oferta antiga que imitastes,

se a Deus não ofertastes pombas duas,

dous olhos de uma pomba lhe of ertastes.

Y apoyándose en el pasaje "... Spritu sancto misso de coelo, in quem desiderant Angeli prospicere", de la primera epístola de San Pedro (i.12), concluye el soneto 36 (a la bofetada recibida por Cristo en casa de Anás) con el chiste de que la ofensa se hizo en la tierra, pero el golpe alcanzó a los mismísimos ángeles del alto cielo. ${ }^{28}$

Como muestran estos dos ejemplos y otros más, ${ }^{29}$ Botelho esmalta parcamente de erudición bíblica sus composiciones, en lugar de apiñarlas en centones sacros a la manera de Marques Pereira o del carioca fray José Pereira de Santana. ${ }^{30}$ A la paciente labor de hacer taracea con múltiples referencias a su sacro saber - como hará después en Conceitns espirituais_, en Lira sacra prefiere el poeta bahiano jugar con unas pocas; en general, y muy de acuerdo con su amor a la simetría, dos por composición: las necesarias para establecer un careo conceptual.

28 "Se os anjos (apesar da humana fúria)/ desejam ver-se nesta face imensa / por ser espelho seu na excelsa cúria,/ venho a entender que nesta dor intensa / chegou ao Céu o golpe desta injúria, / em os anjos se fêz a mesma ofensa." Ocioso sea advertir que no hay irreverencia en Botelho, como tampoco la hubo en la salida, aun más chusca, de Alonso de Ledesma, a quien - en sus Iuegos de Noches Buenas, 1605 - ante el mismo tema se le ocurrió hacer una composición sobre el estribillo del juego de La palmada: "Adivina quien te dio, / que la mano te asentó" (BAE, XXXV, n. 424).

29 Cfr. sonetos 4, 8, 14, 20, 25, 30, 33, 56, 67, 84, 92.

30 La tendencia a parafrasear lugares de las Escrituras, frecuente en obras religiosas, como, por ejemplo, los autos sacramentales Del pan y del palo y $D e$ los Cantares, de Lope de Vega, se hace verdadero centón bíblico, con la indicación de fuentes al pie de la página, en el Peregrina da América (cfr. ed. Academia Brasileira, I, 347-349) de Nuno Marques Pereira, y en la Noticia mística, representación métrica y verdadera bistoria de los abuelos de Maria (Lisboa, 1730) del citado Santana, obra ésta extravagante, especie de acción sacra a la Metastasio, de quien hereda el carioca el gusto por el centón. 
De más importancia es destacar la relación que los mejores versos de Lira sacra tienen con algunos de los más ilustres representantes de la corriente peninsular ( $y$ aun brasileña) de la poesía lírica a lo divino, desde los más antiguos, como fray Íñigo de Mendoza y el padre José de Anchieta, a Góngora y sus imitadores Jerónimo Cáncer y fray Jerónimo Bahía, pasando por Alonso de Ledesma, Lope de Vega y José de Valdivieso. Así, en el principio del bellísimo romance de Botelho "A Circuncisão" (f. 121v):

Consumados ocho dias

padece el niño inocente, ¿qué espera la edad mayor, si la niñez ya padece?

Teniendo fiebre amorosa de que se angustia doliente, manda el amor que se sangre para alivio de la fiebre.

es perceptible la huella de José de Valdivieso,

Ea, amores de mi alma, que os han mandado sangrar, por temer que en el costado una llaga se os hará. ${ }^{31}$

y resuenan ecos de una larga tradición de contrafacta que se remonta al siglo $\mathrm{xv}$, cuando fray f́ñigo de Mendoza divinizó el romance profano "Si eres niña y has amor,/ ¿qué harás cuando mayor?" en

Eres Niño y has amor: ¿qué farás cuando mayor?

. 31 "Romance a la circuncisión y nombre de Jesús", en Romancero espiritual (1612), ed. M. Mir, Madrid, 1880, p. 77. Otros lugares del romance de Botelho confirman su dependencia del de Valdivieso. Cfr. Botelho: "Con el nombre de Jesús / salvar los hombres pretende, / que hace blasón de su nombre / la misma piedad que tiene. / Vence al infierno alcvoso, / y cuando al infierno vence, $;$ como es la primer victoria, / es bien que sangre le cueste" (f. 122), y "Circun[cí]dese el alma / yerros aleves.../ El ejemplo le ha dado / tan buen maestre / que con letras de sangre / lo mismo advierte" (f. 123), con Valdivieso: "Jesús os llaman, amores, / ioh qué lindo nombre os dan! / Seguro podéis decir / que en nombre de Dios entráis. / Con ser Dios el que le toma. / su sangre le ha de costar...", y "Que la letra con sangre entra, / dice el antiguo refrán,/ y pot ninguno se dijo, / mi Niño, con más verdad. / Es letra que a letra vista / en el cielo pagarán, / y más si con vuestra sangre / ven que rubricada va..." (pp. 77-78). 
Pues que en tu natividad te quema la caridad, en tu varonil edad ¿quién sufrirá su calor? ${ }^{32}$

Y las agudezas del bahiano ante el martirio de San Lorenzo, tanto en el soneto 81 ("abrasado de amor e do tormento,/ padeceis de dous fogos o martírio"), como en el romance de f. 106v,

Encruece-se o tirano, e quando vos vê se agasta; se êle tem o peito cru, vós tendes a carne assada.

tienen ya precedente en el padre José de Anchieta

Dois fogos trazia n'alma, com que as brasas resfriou, e no fogo em que se assou, com tão gloriosa palma, dos tiranos triunfou..$^{33}$

$y$ en famoso equívoco de Alonso de Ledesma (Conceptos espirituales, 1600-1612), difundido por el Arte y agudeza de ingenio (discurso xxxiii) de Gracián:

\section{Seréis sabroso bocado para la mesa de Dios,}

32 Véanse, de Dámaso Alonso, Antología. Poesía de la Edad Media y poesía de tipo tradicional (Madrid, 1935), p. 270; también la reed. hecha con José M. Blecua (Madtid, 1956), pp. 141-142, 235-236, y Poesía española. Ensayo de métodos y limites estilísticos (Madrid, 1950), p. 241. Sobre otras adaptaciones del estribillo: Bruce W. Wardropper, Historia de la poesia lirica a lo divino (Madrid, $1958)$, pp. 138-140; añádase a la lista otra composición - análoga en el contenido a la que nos ocupa - de Juan López de Úbeda (1588), en BAE, XXXV, núm. 228.

${ }^{3}{ }^{2}$ Na festa de São Lourenço (ca. 1583). El pasaje continúa: "Um fogo foi o Temor / do bravo fogo infernal .../ Outro foi o Amor fervente / de Jesus, que tanto amava, / que muito mais se abrasava / com êsse fervor ardente / que co'o fogo em que se assava." Cito por la ed. M. L. de Paula Martins, Poesias (São Paulo, $1954)$, p. 733. Este jugar con el asado o con el fuego, desde Berceo en el siglo xIIr a Gabriel Alvarez de Toledo en el xvif (cfr. BAE, XLI, 6), es tan antiguo casi como el martirio del santo, cuyo macabro humor dio pie a éste y a otros chistes: véase nota de Aldrete en Quevedo, Poesía original, ed. J. M. Blecua (Barcelona, 1963), p. 175. 
pues sois crudo para vos

y para todos asado. ${ }^{34}$

Lope de Vega, tan admirado por Botelho, le presta, de sus Rimas sacras, 1614 (f. 60), versos que glosar -aparte de alguna idea y rimas- en las décimas de Lira sacra que comienzan con el mote "Sin Cruz no hay gloria ninguna" (ff. 98-99). El bahiano también extrae del poeta español semilla que florece en conceptos extremados. Por ejemplo, estos versos de Lope (ob. cit., f. 171) a la Eucaristia, limitados por un chiste de alcance sólo local (Caballero de Gracia es el nombre de un oratorio madrileño),

En el Caballero de Gracia

os he visto cada mes

hacer más gracias que el Papa

y más perdones que el Rey

se universalizan en Botelho, substituida una agudeza que no le sirve, por otra (breve círculo de la Hostia-Breve papal) emanada de la principal de Lope (bacer más gracias que el Papa):

Sois nesse círculo breve

Pontífice mais amante, que muitas graças a todos sò por um Breve outorgastes. ${ }^{35}$

El Romancero espiritual (1612) del padre José de Valdivieso, amigo y émulo del Lope sacro, es obra que, igualmente, proporciona materiales.

34 La agudeza jurídica (Viejo Testamento -testamento nuncupativo o abierto) de. Botelho, al final del romance "Ao Santissimo Sactamento": "Fazeis novo testamento / e o primeiro revogastes, / e sendo nuncupativo, / sei que cerrado o deixastes" (f. 101), también es relacionable con el "Testamento de Cristo Nuestro Señor" (BAE, XXXV, $\mathrm{n}^{\circ}$ 278), de Alonso de Ledesma, que inspira igualmente el soneto 51 de Botelho sobre el mismo tema.

35 Lira, f. 101. Los siguientes versos, del romance "Ao Santissimo Sacramento" de Botelho, "Contra o demônio inimigo / nesta Igreja militante, / se nos guarda o vosso corpo, / corpo da guarda o formastes" (f. 100v) y "Dizei-me aqui, que fizestes? / que coisa malfeita obrastes? / Porque estar preso em custódia / sem ter culpa é caso grave" (f. 101); también desarrollan y mejoran en el terreno conceptista posibilidades apuntadas en los de Lope a igual tema en sus Rimas sacras: "...Que viéramos de angelitos, / que como al cuerpo del rey / os hacen cuerpo de guarda, / con chuzos blancos también" (f. 170v) y "... Que puesto que soy villano, / de veros más de una vez / encerrar en la custodia / aquestos latines sé" (f. 171). 


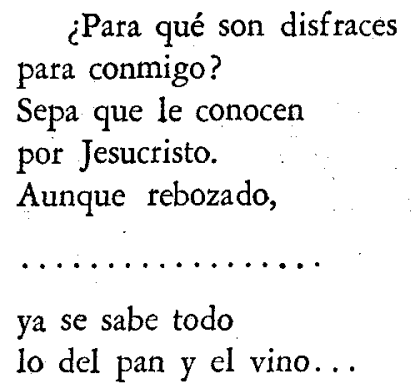

para intensificados (por la bisemia de saber) conceptos en Botelho:

Para que tanto rebuço, para que tanto disfarce?

Que se a pão sabe essa mesa, que sois meu Deus já se sabe. ${ }^{36}$

Naturalmente la deuda con Góngora era de esperar en Botelho de Oliveira. $Y$ asi la períf rasis zodiacal en sus redondillas "Ao Nascimento de Cristo" (f. 86),

\section{Com felicíssimo agouro}

(bem que Dezembro o não sente)

entre o boi que está presente

vejo ao Sol estar no Touro.

procede de un romance al mismo tema por el cordobés:

36 Romancero, ed. cit., pp. 49-50; Lira, f. 100. El aludir a la Eucaristía bajo la imagen profana del galán rebozado (el cuerpo de Cristo oculto bajo las especies del pan) es muy frecuente en los autos sacramentales y versos de Lope de Vega (De los Cantares, El pastor lobo y cabaña celestial, Rimas sacras, ff. 166, 170) y José de Valdivieso (Romancero, pp. 19-20, 175-176, 188, 201, 213-214, 220-221, 233, 304, 313). En Brasil recoge la imagen Gregorio de Matos: cfr. ed. cit., I, 156-157, 174. Otras agudezas de Botelho, como el juego bierro-yerro en f. 122, y los finales del romance "A Circuncisão" (f. 123) y del soneto 90 ("Fran. cisco foi crucificado em Cristo") son relacionables con Valdivieso (ob. cit., pp. 245, 216-217, 315). También lo es (cfr. Romancero, pp. 191-192, 206) la ingeniosa comparación entre la presencia de Dios en la Hostia y los caballeros cubiertos o grandes de España: "Coberto estais, e conheço / que nesta função notável /. justamente vos cobristes / porque sois Senhor mui grande". (f. 101). Bahía prefirió hacer chiste más nacionalista: "Ser Rei dos pães é mui certo, / e assim vos peço esta yez, / que sejais Rei português, / pois que sois Rei "Encoberto" (Fênix Renascida, II, 309). 
$Y$ viendo en tanto diciembre

que los campos más fragrantes

hace un Niño junto a un buey

que el Sol en el Toro hace,

tañen en coros [los pastores]... ${ }^{37}$

A Jerónimo Cáncer y Velasco (Obras varias poéticas, Madrid, 1651; Lisboa, 1657), seguidor del Góngora conceptista y maestro de Jerónimo Bahía, le enmienda galanamente la plana Manuel Botelho de Oliveira, en los siguientes versos, también sobre el Nacimiento de Jesús:

\author{
Sois Cordeito e por melhores \\ companheiros não se estranhem \\ que os brutos vos acompanhem \\ e que vos busquem pastores. \\ Vosso amor verdades lavra \\ no que foi profetizado, \\ porque sois Verbo humanado \\ e sois homem de palavra. ${ }^{38}$
}

37 Obras completas, ed. Millé y Jiménez (Madrid, 1943), n? 92. Alonso de Ledesma ya presentaba al Santísimo Sacramento como el Sol de Justicia que "salió de León, / para entrar en Virgo" (BAE, XXXV, $\mathbf{n}^{\circ}$ 432). Cfr. también Lope de Vega, Kimas sacras, f. 113v. Jetónmo Bahia, en los versos "E porque seja isto assim, / diz porque êste Sol divino / é próspero se em Dezembro / se vê no signo de Virgo./ E o que causa admiração / é que, estando neste signo, / se vê na casa de Tauro, / sendo lugares distintos." (Fênzx, I, 366), patece haber combinado a Ledesma y Góngora. Juégase en estos ejemplos con las dobles significa. ciones de Sol ('Jesús, sol'), Toro ('el buey del Nacimiento', 'constelación Taurus, por la que pasa el sol en primavera') y Virgo ('Virgen Maria', 'constelación'). Y así la Encarnación es comparada a la entrada del sol en la constelación Virgo; y el Nacimiento de Jesús a la primavera. Los versos de Botelho a San Juan de la Cruz (f. 125), "Descalza los pies se vía, / que para al cielo llegar, / lo calzado le embaraza, / lo descalzo corre más", muestran agudeza análoga a la de Gón. gora sobre Santa Teresa de Jesús, también carmelita descalza (ed. cit., p. 145).

38 Lira, f. 85v. Se inspiran en unas quintillas de Cáncer donde lo jocoso raya con la grosera irreverencia (cito por la ed. de Madrid, Manuel Martín, 1761, p. 102): "Dos brutos al Verdadero, / assisten, y uno le adula, / con instinto muy sincero; / pero el otro compañero / creía en Dios como una mula./ Un cherub al más dormido / hace que los ojos abra, / diciendo con gran ruido: / ¡Hombres, ya el Verbo ha nacido, / cuidado con lo palabra!" La agudeza Verbo-palabra fue antes empleada por Lope de Vega (Rimas sacras, f. 17iv) y deja huella en Bahía (Fênix, II, 311). En versos a San Antonio, "Quando o burel estimastes / na carreira do cuidado, / com Francisco emparelhado, / dizem lá que encordastes" (f. 94v), juega Botelho con los sentidos 'cingir o cordão franciscano' y 'dar com a lança na corda e não enfiar a argolinha' (en carreras y juegos de cañas, pero aquí con arcana alusión a la castidad de ambos santos) de encordar, de modo. análogo a Cáncer que, refiriéndose a San Francisco, dice: "Es desagradecido, / y al que le halaga / con el cordón suele / dalle las gracias" (p. 52). En menos. ocasiones. Botelho conserva el mal gusto de la fuente. En el soneto 89 llama a 
Pero, con todo, Jerónimo Bahía parece ser su fuente predilecta. Así, en estas redondillas a la Natividad (f. 85v):

Sempre teve o mundo falhas, e por esse desprimor, como é tão mau pagador, vos pagou o mundo em palhas.

despreciando la tentación de otros conceptos sobre pajas, ${ }^{39}$ sigue más de cerca al poeta portugués,

Devendo-vos tanto o mundo, vos deu tão humilde cama, mas vós de mau pagador em palhas tomais a paga.

(Fênix, II, 311-312)

que a Ledesma, modelo de agudezas sacras:

$$
\begin{aligned}
& \text { Señor, ¿pajas por alhajas } \\
& \text { sacáis por prenda al deudor? } \\
& \text { - Sí; que del mal pagador } \\
& \text { cobrar, y siquiera en pajas. }{ }^{40}
\end{aligned}
$$

Santo Domingo "perro leal", que defiende a la Iglesia con sus ladridos (sermones), rebajando poco la zafiedad de Cáncer (en p. 99: Santo Domingo se puso "hecho un perro" contra los herejes), tal vez autorizada por el precedente de Ledesma, para quien era "perro ventor el Baptista [San Juan]; / y pues es perro de brio, / echalle en el rio". (BAE, XXXV, no 391).

39 Góngora: "Esta noche un Amor nace, / niño y Dios, pero no ciego, / y tan otro, al fin, que hace / paz su fuego / con las pajas en que nace" (ed. cit., no 173); Cáncer: "Cuando el yelo se hacía rajas, / y tanto el frío sentía, / que con todos reñiría / por quítame allá esas pajas, / entre pajas arrojado, / nuestra culpa satisfizo; ; ah buen Dios enamorado! / ¿Vos por el hombre encarnado? / ¿Vos por el hombre pajizo?" (p. 102); Bahía: "Sobre palhas vos lançou [o mundo], / e toda gente se espanta / que sendo lume dos olhos, / vos faça lume de palhas" (Fênix, II, 132).

40 En BAE, XXXV, n" 581. El chiste se hace sobre el refrán "Del mal pagador, siquiera en pajas" (Covarrubias, Tesoro, s. v. paja); José María Sbarbi, Gran diccionario de refranes de. la lengua española (Buenos Aires, 1943), p. 737, registra "La mala paga, siquiera en pajas", y explica: "Recomienda que se tume aquello que se pueda por no perderlo todo, pues más vale poco que nada." Cfr. "De ruim pagador, em farelos recebe", en Pedro Chaves, Rifoneiro portguês (Porto, 1928), p. 94. En otra composición de Botelho al mismo tema hay: "Eritre pajas pobres / el Niño se vio, / que el trigo entre pajas / siempre está mejor" (f. 120-120v), donde pudo combinar a Lope de Vega, "Manso Corderito / ... blanco trigo en pajas..." (BAE, XXXV, no 488), y a Bahía: "que a neve desse vosso corpo bello / entre palhas bem pode conservarse" (Fênix, III, 212). 
También al principio de la misma composición,

Meur Jesus, meu Pequenino, quero-vos falar de chança, como brinco de criança, como jôgo de menino.

Botelho tiene más en cuenta a Bahía,

Hoje, meu Deus, meu Menino, vos hei de falar de chança; que um menino não quer veras, um Deus sempre estima graças.

(Fênix, II, 310)

que a la fuente del portugués, Jerónimo Cáncer:

De chanza, Señor, os hablo; todo el buen gusto me tiembla, que no soy hombre de burlas, y sois dizque Dios de veras. ${ }^{\mathbf{1 1}}$

Asimismo estos conceptos eucarísticos, en los ff. 100-101 de Lira sacra,

Entre acidentes que vejo na pequena quantidade, tendes êsses acidentes sentindo a fcbre de amante.

Que regalada iguaria tão exquisita e suave, ou se chame manjar branco ou papo de anjos se chame! Os que vos querem de veras vos amam com muito exame,

41 Ed. Madrid, 1761, p. 56. Cfr. también Bahía: "Ao Menino de Belém / me deixem falar em chança, / que posto que é pequenino, / por Deus tem imensa graça" (Fênix, IV, 67-69). Para un eco de estos pasajes en Sebastião da Rocha Pita, cfr. Mello Moraes Filho, Parnaso Brazileiro (Río de Janeiro, 1885), I, 8890. Sobre la deuda de Bahía a Cáncer, véase J. Ares Montes, Góngora y la poesía portuguesa del siglo XVII (Madrid, 1956), p. 461. 
bem que a bocados vos comem, bem que em fatias vos fazem.

Inda que estejais exposto sempre oculto vos mostrastes, e quereis estar oculto porque o culto não vos falte.

se derivan de Jerónimo Bahía. ${ }^{42}$

A pesar de los ejemplos precedentes, y como ya se echa de ver en las notas que los acompañan, no es tarea fácil aislar la fuente principal de Botelho (más ligado a una corriente que a determinado autor), ${ }^{43}$ pues sus rcferencias al tico acervo conceptista de la poesía a lo divino ce los siglos XVI y XVII se entrelazan como cerezas en cesto: se quieren sacar dos y salen seis. ${ }^{44}$ La complejidad se extrema en las composiciones

42 Cfr. Fênix, II, 308; I, 362-364 (romance "Ao Menino Deus em metáfora de doce", que ya habia aprovechado Botelho en Música do Parnaso, I, 143-145); II, 306 y 308, así como IV, 68; II, 358. Las agudezas eucarísticas a base de dulces son antiguas: cfr. Joan de Timoneda (BAE, LVIII, 99, 103: manjar blanco), José de Anchieta (ed. cit., p. 383: doce bolo), Valdivieso (BAE, XXXV, no 463: mazapán, como toledano que era el poeta). Otros versos de Botelho, de su composición "Ao Nascimento de Cristo" (ff. 85-86), deben su inspiración a Bahía: cfr. "Quando, como os mais humanos, / estais de panos coberto, / vos pôs o mundo em aperto / e vos deu o mundo uns panos" con Fênix, II, 311; y "Com vossa mãe Virgem bela / igualmente estais ornado: / vós vos vestis de encarnado, / ela de carne de donzela" con Fênix, loc. cî., y asimismo con Valdivieso (Romancero, p. 176), Góngora (ed. cit., no 167, p. 310) y Cáncer, p. 102.

43 Esto lo demuestra, por ejemplo, el siguiente juego de palabras: "Se sois Deus por pãa dos homens, / como pobre e miserável, / päo por Deus quero pedirvos / para poder sustentar-me" (f. 100), de Botelho, que difícilmente pudo inspirarse en el villancico "deste pan comeldo vos, / que si pedís pan por Dios / os darán Dios por pan", del mejicano Coloquio de la nueva conversión y bautismo de los cuatro últimos reyes de Tlaxcala en la Nueva España, atribuido a Cristóbal Gutiérrez de Luna, 1619. Cfr. José J. Rojas Garcidueñas, El teatro de Nueva España en el siglo XVI (México, 1935), p. 221. Agradezco esta noticia al profesor Winston A. Reynolds, quien, en comunicación ante el III Congreso de la Asociación Internacional de Hispanistas (México, 1968), muestra la filiación del citado Coloquio con Lope de Vega.

44 Cfr., por ejemplo, estos versos de Botelho a la Eucaristía, "Se estais partido, conosco / quis vosso amor concertar-se, / e por isso, a bom concêrto / êsse partido aceitastes" (f. 100v), con Valdivieso ("que entre El y el hombre / ya no hay pan partido", Romancero, p. 50). Góngora ("El pan que véis soberano /...se da más entero / adonde más dividido", ed. cit., n $\mathrm{n}^{\circ} 140$ ) y Bahía: "Em vós se vê, pão sagrado, / todo o algarismo perdido, / pois quando sois repartido, / então sois multiplicado" (Fênix, II, 306). O el romance de Botelho a San Juan de la Cruz (ff. 124́v-126), que comienza "Oigan, caballeros, oigan, / y atentos han de escuchar, / que es para nuevas de gusto / la atención comodidad", siguiendo al parecer tanto a Cáncer ("... atención, señores, pido...", p. 95), como a Bahía ("Ora ouçam da minha Arte, senhores...", Fênix, I, 367). O, en fin, 
en que nos hemos apoyado aquí para rastrear las fuentes de inspiración de Botelho, principalmente las hechas en torno a la Eucaristia y Natividad, temas trillados si los hay, y especie de obligatorio tource de force para todo ingenio seiscentista en trance de divinizar. A esto se puede añadir, para hacer casi imposible determitiar qué hilos sigue Botelho, el que los poetas de la época estimasen el legado de agudezas sacras como propiedad común. Sobre todo, después que Gracián las reunió en el recetario del siglo, su Arte y agudeza de ingenio (1648), que parece haber sugerido algunas al poeta bahiano. ${ }^{45}$

No obstante estas dificultades, espero que nuestro análisis haya probado: primero, que Lira sacra se entronca con la corriente peninsular y americana $^{46}$ de la poesía a lo divino, poesía que, precisamente por su

la siguiente agudeza, al Nacimiento de Cristo, que tiene análoga base social en Botelho ("Neste retiro previsto / de Belém considerei / que sendo filho de um rei, vos vejo um pobre de Cristo", p. 86), en Cáncer ("y el que se vio con tres reyes, / dixo, esta vez yo soy hombre", ob. cit., p. 104) y en Bahía: "quem já vos chamou Senhor, / hoje criado vos chama" (Fênix, II, 311).

$45 \mathrm{Y}$ a vimos antes que Botelho pudo haber leído un texto de Ledesma en el libto de Gracián. Hay otros casos más (cfr. remates de los sonetos 37 y 42 de Lira con Arte, ed. Aguilat, 1944, p. 74), y entre ellos, dos relacionables con pasajes de Giambattista Marino aducidos por Gracián en los discursos xvi y xvii de su Arte. Así, Botelho en estos y otros versos de un romance a San Esteban (ff. $123 \mathrm{v}-124 \mathrm{v}$ ), "Si está de piedras herido / vuestro invencible valor, / para corona de mártir / preciosas piedras formó", parece haber tenido más en cuenta los del italiano ("... Furo a te gemme preziose $i$ sassi / che celeste corona al crin ti fero"), publicados en 1602 entre las "Rime sacre" de La lira, que los de Ledesma ("Esteban, un lapidario, / muerto por recoger piedras, / y no de los orientales./ ...Acá le tenían por loco,f ... pues le vemos hacer dellas / rubíes finos y hermosos, $/$...saca sus piedras preciosas...", BAE, XXXV, $\mathbf{n}^{9}$ 318), insertos en sus Conceptos espirituales (1600-1612), o los del propio Bahía (ob. cit., IV, 48) a igual tema. También los versos "y haciendo [joh Herodes!] injustas heridas / en sus cuerpos, les verás / multiplicadas las bocas / que publican tu impiedad", en romance de Botelho " $\dot{A}$ morte dos Inocentes" (f. 120v), engarzan fino concepto, muy repetido on las letras, desde Shakespeare. (Julius Caesar [ca. 1599] III.i.259-262) a Calderón de la Barca (La vida es sueño [1635] III.xiii. 39-48), Gabriel Bocángel y Unzueta (La lira de las Musas [1637] f. 77v) y Sor Juana Inés de la Cruz (letrilla publ. en 1692: cfr. Obras com. pletas, ed. Méndez Plancarte, I, 29), y que ya aparece en madrigal de Marino a la llaga del costado de Cristo (La lira, 1602, II, madriale cxlix) citado por Gracián: "Piaga dolce d'amore,/ già tu piaga non sei, / ma bocca di quel core / che parla ai sensi miei; / e quante in te consperse / son stille sanguinose, / tanto son per mio ben lingue amorose." Marino repite la imagen en La strage degl"Innoconti. 1632: "Piaghe felici, ..., ... di grazzia e d'amor lingue loquaci..." (II, oct. 196). Cfr. también E. de Matos, Ecce Homo (Lisboa, 1677), pp. 2, 51, 53. ${ }_{46}$ No conozco estudio de conjunto sobre la poesía lírica a lo divino en Portugal, Brasil o la América hispana, y es pena que estos campos no hayan merecido la atención de Wardropper, quien ni siquiera menciona a Sor Juana Inés de la Cruz en su excelente Historia de la poesía lírica a lo divino. En Portugal todavía están inéditas (en la Biblioteca Cadaval) unas Obras poéticas del canónigo Julião Maciel (fallecido en 1717), llenas de airosas cancioncillas populares a lo divino. También necesita ser estudiada la literatura de cordel a lo divino, representada por abundantes folletos, anónimos, de villancicos en portugués y español, a diversos 
índole religiosa, es con preferencia conceptista; segundo, que, decidido Botelho a seguir tal corriente, lo hizo con la actitud propia de su época ante el uso de las fuentes. ${ }^{47}$ Las invenciones de sus antecesores forman parte de la etudición poética "propia"; erudición que es base (y no por sacra menos legítima que la humanística) en que intentar una creación personal. Y ésta, en sus mejores ejemplos viene a ser - como los pasajes aqui citados muestran- una valiosa réplica que, si evidencia la tradición en que se mueve, también permite a Botelho dar a entender su propio perfil de desapasionado espíritu racional, aficionado al orden, la simetría y el primor diminuto.

\section{Religiosidad de Botelho de Oliveira}

Aquella mania de Botelho por el cotejar pareado de las ideas y por las fórmulas de simetría estilística a que aludimos antes, revela, aquí como en Música do Parnaso, la mentalidad normativa del abogado bahiano, encuadrando en fríos esquemas racionales todo posible exceso de sensaciones o de conceptos. $\mathrm{Y}$ esto compagina bien con el tono desapasionado de su religiosidad, en que lo santo es objeto de agudeza, o que se manifiesta en la adhesión escolásticamente argumentada hacia unos dogmas y preceptos en el fondo aceptados sin discusión y acaso sin haberlos comprendido ( $\mathrm{ffr}$. nota 18). Me explico: frecuentemente en su libro, y este es el lado menos bello, nuestro abogado poeta emprende, con todos los resabios de su formación escolástica, la defensa de las verdades de su religión, haciendo sentir al lector - al parecer temido incrédulo o ignorante por el poeta- que todo el edificio religioso está puesto en tela de juicio. De esta manera, en lugar de lírica emoción ante la fe, en Lira sacra dominan el juego conceptual o una dialéctica fría, de sintaxis machacona, embarazada de lañas lógicas y vocabulario legal o filósofico. ${ }^{48}$ Por ello la lírica religiosa de Manuel Botelho de Oliveira

santos y fiestas religiosas, que se cantaron en templos portugueses, y sin duda brasileños, en los siglos XVII y xvIIr y que propagan, prácticamente hasta nuestros dias, los contrafacta más antiguos. Con este tipo de literatura se relaciona la poesía misional, hecha sobre letrillas y romances populares, del jesuita José de Anchieta, cuyo antepasado, el maestro de capilla Juan de Anchieta, fue autor de notables contrafacta musicales.

47 Cfr. Gracián, Arte y agudeza lix: "Es de notar que unas veces discurre el ingenio por invención; otras, por elección: así que no siempre se inventa; ayúdase la elección de la erudición, y aun la misma invención para llenar y para aplicar, se vale de ella."

48 Cfr. son. 37: "Porem se Cristo é Deus, bem significa / que se êle [Caifás] dis que Cristo ha blasfemado / o Pontífice então blasfemo fica", o en $f$. 70: "...logo não pode haver vício profano, / que a mesma carne sois sacramentada, 
contrasta notablemente con la de sus predecesores brasileños en este género, quienes, a pesar de prestar el homenaje debido a las exigencias conceptistas del campo, lo sobrepasan con viva efusión cordial. Recuérdese al padre José de Anchieta, pleno de fresco temblor y júbilo de santo misionero. $\mathrm{Y}$ a fray Eusebio de Matos, que anima el lujo gongorino de sus cuadros de la Pasión ${ }^{49}$ con afectivos ecos camonianos. $Y$, en fin, hasta en el desvergonzado Gregorio de Matos, que por no faltar a sus malas costumbres, lloró sus contricciones en versos hurtados, ${ }^{50}$ hay, para decirlo con palabras suyas, una "brava condição" de "peito apaixonado" (I, 121), estremecido por el patético reconocimiento de su irremediable "intento e costume de pecar" (I, 117).

En suma, es clara en Botelho la incapacidad de sentir hondamente la religión (lo mismo le sucedió con el amor en Música do Parnaso) como un poder central y absorbente a que subordinar todo y someterse él mismo. Más bien, aunque de manera tímida y en pocos casos muy explícito, parece orientarse a lo opuesto: a un reducir la infinitud aplastante de lo sacro a racionales ${ }^{51}$ dimensiones humanas, de modo que la religión sea sentida al servicio del hombre y no al revés. Esta tendencia

/ assim que celebramos com vẹntura / que é pura a Conceição e a hóstia pura." Cfr. también sonetos 2,11 y 35 ; sonetos 46 y 51 para léxico jurídico; son. 8 y ff. $86 \mathrm{v}, 108$, para ejemplos de terminología escolástica.

49 Me refiero a las cuatro composiciones sobre la Pasión de Cristo y otra "A Soledade da Virgem Maria", publicadas como "litigiosas entre os dois irmãos Gregorio e Eusebio de Matos", por F. A. de Varnhagen en su Florilegio da poesia brazileira (ed. Academia Brasileira, 1946, I, 157-162, 165-168). Estas composiciones y otras 12 más sobre el mismo tema, inéditas, son de Eusebio de Matos, como pruebo en trabajo de próxima publicación.

50 Tanto el "católico incidente" del arrepentimiento de Matos viendo un crucifijo y componiendo su soneto "Pequei, Senhor, mas não porque hei pecado..." (I, 91), como el menos católico a la hora de morit, cuando, viendo en las manos del sacerdote que lo asistía "um Crucificado com os olhos cobertos de sangue", se le ocurrió decir "Quando os meus olhos mortais / ponho nos vossos divinos, I cuido que vejo os meninos / do Gregorio de Morais" (V, 357), que parecen piadosas -o impías- invenciones de sus biógrafos (cfr. Obras, ed. cit., I, 32$33,88)$, son arreglos, no muy libres, de composiciones ajenas. El texto último es, literalmente, la secularización irreverente de los versos "Quando meus olhos mortais / ponho nos vossos divinos, / com affectos tam benignos / estou vendo me chamais; / com braços abertos estais / dizendo-me: oh peccador,/ a meus pes já te vem pôr, / chega-te a êste meu lado, / que se é grande o teu peccado,/ mayor é o meu amor...", anónimos, copiados en manuscrito de la Bibl. Nacional de Lisboa (FG.8625, p. 302), donde se recogen algunas composiciones de Tomás Pinto Brandăo, amigo de Gregorio de Matos y cuyas obras frecuentemente corren bajo nombre del bahiano. En cuanto a las fuentes del soneto mencionado, véase Sílvio Júlio, Reaçôes na literatura brasileira (Río de Janeiro, 1938), pp. 131-132.

51 Botelho, significativamente, gusta del término, aplicado a la conducta humana. En su comentario al octavo mandamiento, en los Conceitos espirituais, aparecen los cultismos rational y rationável, con una grafía latinizante que denuncia el origen escolástico y la novedad de su empleo en lengua vulgar. 
ya es inherente a la literatura a lo divino, pues que al divinizar lo humano se seculariza en parte lo sagrado, así es que Botelho no tiene más que acentuar un tanto el atrevimiento de sus agudezas para dejar entrevisto su propósito. Y, en efecto, su complacencia en presentarnos a Cristo postrado a los pies del Demonio, ${ }^{52}$ igualado a Santiago el Menor, ${ }^{53}$ e inferior a San Francisco de Asís, ${ }^{54}$ bien puede ser no más que una libertad extravagante y nada rara - aunque censurable ${ }^{55}$ - en la época, pero también no deja de apuntar hacia una merma de la terribilidad numinosa del Dios-Yavé en favor de un crecimiento de lo humano. Botelho azucara muy bahianamente la trágica imagen de la vida como conflicto entre lo terreno y lo divino cuando llama "doce guerra" (son. 117) a la de este mundo contra el sobrenatural. $Y$ su Señor es más bien el redentor del hombre, por quien "la tierra al cielo se unió" (f. 119), que aquel inexorable juez todavía tonitronante en la pluma de Nuno Marques Pereira, moralista estrecho que, escandalizado por las costumbres bahianas, daba la bienvenida a enfermedades y terremotos como castigos del Cielo, y se regocijaba de que Dios no permitiese el progreso de la medicina. ${ }^{56} \mathrm{Nada}$ más contrario a esto que el soneto 116, "Ao contágio

52 En el son. 32, "Ao lavatório de Judas", se aprovecha Botelho de la situación y, retorciendo la idea de que el Demonio está dentro de Judas, concluye que Jesús al fin sucumbió a la tentación satánica que antes supiera vencer (Mateo iv. 8-10), "Pois lavando ao discípulo malvado, / se de Judas aos pés está por terra, / Cristo aos pés do Demônio está postrado". Lo mismo en f. 80v: "nesta ação mostrando / ... a verdade postrada à mentira."

53 Soneto 76, a Santiago el Menot, "por irmão de Cristo conhecido" para Botelho, quien, muy a la manera hispánica (cfr. Américo Castro, España en su bistoria, Buenos Aires, 1948, cap. iv) toma al pie de la letra las Escrituras (Mateo xiii.55; Gal. I.19). Dice así a Santiago: "Na vida nem na morte vos excede / o mesmo Cristo, que antes repetistes / igual ação que am ambos vos sucede: / pois quando os inimigos conseguistes, / Cristo na cruz perdão por êles pede, / vós pot êles perdão na cruz pedistes" (F).

54 Soneto 90: "...Tivestes melhor cruz que Cristo amado / nesta impressão das chagas, porque nisto / a Cristo pareceis avantajado..." Cfr. también f. $75 \mathrm{v}$, aludiendo a la estigmatización del santo: "Pórem neste mistério soberano / Cristo se avantaja milagroso, / que inda que tem Francisco o ser humano, / neste martírio o excede venturoso...", y en $f$. 76 , donde, por haber derramado San Francisco su sangre en segunda crucifixión, se dice "que redentor do mundo se venera".

55 A fray Vasco de Castelbranco, franciscano, en Évora 1590, la Inquisición le ordenó desdecirse en el púlpito, entre otras, de las siguientes proposiciones predicadas: 1) "São Francisco é mais honrado mártir que Cristo Nosso Senbor, porque teve mais honrado algoz"; 2) "Ninguém se pode salvar senão sendo devoto de S. Erancisco"; 3) "S. Francisco é segundo filho natural de Deus porque the deu Deus suas armas diretas." Cfr. J. Mendes dos Remedios, Os judeus em Portugal, II (Coimbra, 1928), p. 27.

56 Cfr. O peregrino da América, I [1728], 130-131, 227, 397; II [1733], 85, 129-131, 102-103, 111-112, 227, 233. Cito por la ed. Academia Brasileira, Río de Janeiro, 1939. En contraposición a Marques Pereira (I, 150-151), que era portugués, el benedictino brasileño Loreto Couto, en sụs Desagravos do Brasil, 1757 
das doenças" (venéreas, según parece), donde Botelho limita el poder punitivo de Dios en nombre de una misericordia nacida del respeto básico a la criatura humana, al fin, imagen de Dios:

Senhor, se nos castigos fulminados intentais a vingança merecida, terá seu fim, Senhor, a humana vida, mas não terão seu fim nossos pecados.

Bem conheceis os ânimos errados, a inclinação dos homens distraida onde mora da carne a torpe lida, onde nascem do mundo os vãos cuidados.

Bem que seja, Senhor, a culpa nossa nem por isso negueis vossos favores, e mais que vós a culpa vil não possa.

Não derrubeis aos homens com furores, que derrubais, Senhor, a imagem vossa, e contra vós mostrais êsses rigores. ${ }^{57}$

ENRIQue MaRTíNez López

University of California,

Santa Bárbara.

(publ. Río de Janeito, 1904), cap. xiii, sostenía que no era pecado el que los esclavos trabajasen en las plantaciones de caña de azúcar los domingos y días santos. Tampoco creía pecado mortal la "simples fornicação, vingança e semelhantes" (p. 340) entre indios no evangelizados.

57 Este soneto muestra bien que la religiosidad de Botelho es muy luso-brasileña. Gilberto Freyre hace notar en su Casa Grande \& Senzala (ed. J. Olympio, Río de Janeiro, 1958), I, 346, que "Um catolicismo ascético, ortodoxo, entravando a liberdade aos sentidos e aos instintos de geração, teria impedido Portugal de abarcar meio mundo com as pernas". Para la diferenciación entre la religiosidad "mais frouxa, mais relassa" del luso-brasileño y la del hispanoamericano, emanada de una Castilla "dramáticamente católica", cfr. I, 29-30. 
